\title{
LA CIUDAD DESDE EL PERIODISMO LOCAL UNIVERSITARIO, UN CASO
}

\author{
Mireya Barón Pulido* \\ Recibido: abril 24 de 2006 - Revisado: junio 19 de 2006 - Aceptado: julio 4 de 2006
}

"Que el hombre de la calle también es histórico, es un axioma reconocido en nuestra época por las ciencias sociales"

Juan José García posada

Periodismo y ciudadanía

\section{Resumen}

Este artículo es un reporte de caso que presenta los resultados finales del proyecto" "Tendencias del Periodismo Local Universitario UPZ 99 Chapinero" realizado durante 8 meses en las 4 universidades del sector que cuentan con programas de comunicación social. Se trabajó con los respectivos emisores y audiencias de los periódicos: Expresiones (Politécnico Grancolombiano), Fe de Erratas (Javeriana), Gaceta Libertadora (Los Libertadores) y Escenario (Santo Tomás). Se evidenció que el interés de este ejercicio periodístico universitario se centra en hacer visible las narrativas de los ciudadanos del común, sin embargo la prelación en cuanto a los actores se ciñe a la población estudiantildocente; el grupo focal lector, por su parte, considera que este ejercicio periodístico aún es incipiente y que se debe superar "lo banal" y la actitud de denuncia. El uso de fuentes de la "ciudadanía del común", que busca un mecanismo de participación y lo puede hallar en el periodismo universitario, es aún tímido, si bien se percibe una preocupación por trabajar un periodismo desde el "estar ahí antropológicamente".

Magíster en Lingüística Hispanoamericana y Española. Coordinadora Editorial del Periódico Escenario 2002-2005. Docente-investigadora y Coordinadora de Planeación de la Facultad de Comunicación Social.

El actual proyecto fue aprobado en la pasada Convocatoria de Proyectos de Investigación que realizara la Vicerrectoría Académica y la Unidad de Investigación en noviembre del 2005, y contó con el respaldo financiero y la asesoría operativa de la Unidad de Investigación. El proyecto hace parte del Grupo de Investigación de la Facultad: Comunicación, Paz, Conflicto; específicamente de la línea Comunicación y Ciudadanía, en la que se busca rescatar la percepción de ciudad como espacio potenciador de cultura y comunicación. 


\title{
Palabras clave
}

Periodismo local, Periódicos de facultades de Comunicación social, Chapinero, Análisis de contenido.

\begin{abstract}
This article is a report of a case that presents the final results of the "Tendencies of Chapinero 99 UPZ University Local Journalism" Project performed during 8 months in the 4 universities of the sector and which have social communication programs. We worked with the respective newspapers: Expresiones (Politécnico Grancolombiano), Fe de Erratas (Javeriana), Gaceta Libertadora (Los Libertadores), and Escenario (Santo Tomás). It was evident that the interest of the University Journalist Exercise is focused in making visible the narrative of the common citizens, and yet the precedence regarding the actors is focused on the student - teacher population; the reading group considers that the journalist exercise is still incipient and that it must overcome the "banal" and the attitude of denunciation. The use of sources of the "Common citizens" that try to find a participation mechanism and find it in a university journalism is still shy although there is a concern to work for a journalism since the "being there anthropologically".
\end{abstract}

\section{Key words}

Local Journalism, Newspapers of the Social Communication Faculties, Chapinero, Content Analysis.

\section{Descripción del proyecto}

El ciudadano del común, la localidad, el barrio, "the neighborhood" buscan cada día ser escuchados y convertirse en sujetos dialógicos-partícipes de las múltiples experiencias locales que consolidan el tejido de la ciudad y, por qué no, del país. Por ello, resulta valioso acercarse a la creación de medios impresos universitarios, particularmente de la Localidad en la cual se halla inmersa la Universidad Santo Tomás -Facultad de Comunicación Social-, con el propósito de analizar cuáles son las prioridades de los medios creados por las Facultades de Comunicación Social del sector, y cuáles las prioridades de "Ios ciudadanos del común". La acade- mia se ha acercado en los últimos años a revisar con otros criterios el ejercicio de un periodismo que dé cabida a la ciudadanía del común.

Por ello, la actual investigación, sin querer decir con ello que es el único marco de referencia, acoge la revisión que hizo la investigadora colombiana con el proyecto de voces ciudadanas desde un periodismo público, haciendo alusión a las particularidades de la sociedad colombiana y del nivel de su participación en el periodismo, con sus actores y tejidos sociales múltiples, variados y desiguales. Por ello, se considera valioso destacar los siguientes tópicos que resultan viables a analizar en la muestra seleccionada: 


\section{Tópicos del periodismo público²}

\begin{tabular}{|l|l|}
\hline \multicolumn{2}{|c|}{ Tópicos a revisar } \\
\hline $\begin{array}{l}\text { Democracia deliberativa a partir de una esfera pú- } \\
\text { blica central. }\end{array}$ & $\begin{array}{l}\text { Democracia radical a partir del reconocimiento de } \\
\text { los diferentes contrapúblicos, de sociedades } \\
\text { estratificadas y desiguales. }\end{array}$ \\
\hline $\begin{array}{l}\text { Consenso, negación del disenso. } \\
\begin{array}{l}\text { Formas comunicativas argumentativas. } \\
\text { Protocolos de estilo al hablar - el mejor uso de la } \\
\text { palabra. }\end{array}\end{array}$ & $\begin{array}{l}\text { Disenso: visibilizar las diferencias a partir de dos } \\
\text { principios, la libertad y la igualdad. }\end{array}$ \\
\hline $\begin{array}{l}\text { Acuerdo entre pares - visión bipolar de los actores } \\
\text { sociales. }\end{array}$ & $\begin{array}{l}\text { Identión. } \\
\text { lúdica. }\end{array}$ \\
\hline
\end{tabular}

\section{Problema actual}

En el marco de las ciencias sociales, en el caso particular para el campo del periodismo, resulta crucial revisar de manera juiciosa el ejercicio periodístico promovido desde la academia, su papel frente a las necesidades del contexto y el grado de reconocimiento entre los actores sociales de dicho proceso comunicativo: emisores-lectores. ¿Qué tendencia de periodismo creado desde la universidad caracteriza el sector UPZ 99 Chapinero, teniendo en cuenta los lineamientos del periodismo público y su relación con la agenda ciudadana? En otros términos, y desde el ámbito de la comunicación como espacio potenciador y forjador de educación, icuáles son las prioridades de los medios impresos universitarios y de los "lectores ciudadanos del común" en el sector de Chapinero?

\section{Objetivo}

Evidenciar las posibles percepciones del periodismo escrito elaborado por las Facultades de Comunicación
Social y su proximidad con las necesidades de la ciudad, a partir de lo local

\section{Descripción de la metodología}

"Tendencias del Periodismo Local Universitario" es una investigación aplicada -descriptiva, apoyada en el proceso de sesiones con grupos focales y los procesos de interpretación que exige el análisis de contenido en las muestras escritas y se sustenta en el trabajo etnográfico que realizaron tres estudiantes en su práctica profesional de periodismo. Desde el marco metodológico, la investigación se desarrolló en dos etapas: a) Trabajo con 5 grupos focales entre emisores-lectores, cada uno entre 10-12 personas, y b) Análisis de contenido (AC) de las muestras periodísticas, sustentado en la sistematización de estudios de carácter cualitativo que brinda el software Atlas/ti, al categorizar los enunciados Titulares y uso - tipo de fuentes.

Esta Tabla resume los aspectos a analizar, como un ejercicio de auto revisión que hace la investigadora Ana María Miralles en su conferencia: "Comunicación y conflicto, hacia la necesidad de politizar los antagonismos", En: Congreso Internacional La comunicación, eje transformador de los conflictos hacia la convivencia pacífica, Bogotá, Universidad Santo Tomás, 6/05/06 (Memorias en proceso). Para mayor detalle, consúltese: Barón Pulido Mireya, "Tendencias del periodismo Local Universitario, una mirada", Revista Miradas: Comunicación y Ciudadanía, Vol 1, N³, julio-diciembre de 2006, pp.283-297. 
Dado que los resultados se apoyan en el cotejo de datos arrojados en las sesiones con los grupos focales y el $\mathrm{AC}$, a continuación se presenta el conjunto de inferencias haciendo el respectivo cruce de datos.

El corpus para realizar el respectivo AC, haciendo uso del software Atlas/ti, fue de 52 artículos periodísticos (PD: Documentos Primarios, RTF), nomenclados así:

PD 1 al PD 15, periódico Expresiones; PD 84 al PD 107, periódico Escenario; PD 59 al PD 65, periódico Fe de Erratas; PD 111 al PD 117, periódico Gaceta Libertadora. En el reporte de citas hipervinculadas a los códigoscategorías del AC: Voces ciudadanos del común, se compilaron 107 documentos primarios entre textos-artículos periodísticos y fotografías.

La caracterización del grupo focal de audiencias se organizó acorde con los datos suministrados por el grupo emisor. Se trabajó con 20 ciudadanos del sector distribuidos entre la academia y el comercio: 4 docentes, 7 estudiantes y 9 comerciantes.

Por demás, se debe mencionar que en este tipo de proyectos surgen algunas particularidades que, aunque son de orden técnico, afectan la marcha del proyecto. Se debe advertir que en este tipo de ejercicio periodístico, la universidad publica un número limitado de ediciones, así, para obtener la edición impresa y en magnético de cada ejemplar, se debió solicitar dicho material a las respectivas editoriales y/o talleres de arte gráfico de cada facultad, proceso que demandó tiempo para poder contar con las respectivas ediciones, punto neurálgico para la investigación.

\section{Análisis de resultados}

Después de un proceso de inducción a los tres practicantes de periodismo con el reconocimiento y apropiación básica del software Atlas/ti, se procedió a la ubicación de categorías desde el Análisis de contenido en cada uno de los artículos ingresados en el software, proceso que permite sistematizar con cierto rigor y visualizar las posibles relaciones de contenido entre las categorías a analizar, las muestras discursivas en donde se hallan dichas categorías y algunos datos de tipo analítico que a lo largo del proceso de lectura hallan los investigadores.

En lo que concierne a la primera categoría del $\mathrm{AC}$, uso de Fuentes, se debe entender que la "fuente misma debe aceptar y asumir su condición de copartícipe de la responsabilidad social de informar" y por ende "la legitimidad de la información y su grado de veracidad no están dictados por la índole de la fuente de información sino por la calidad de los datos que se obtengan en la búsqueda de los elementos informativos en las fuentes más diversas" (Daza Gladis et all, 2000, p. 106). El corpus analizado sugiere el siguiente comportamiento en lo que la actual investigación denominó como categorías de análisis: Fuentes Ciudadanía (FC), Fuentes Autoridades Locales (FAL), Fuentes Autoridades Nacionales (FAN), Fuentes Expertos (FE).

Para la comprensión de los siguientes gráficos (networks, redes semánticas, diseñadas desde el software por los investigadores a partir de las categorías de análisis acordadas), es pertinente aclarar el uso de cada icono y su proceso de lectura:

- El gráfico se lee de arriba hacia abajo, entendiendo que el nivel superior corresponde a una forma discursiva que sustenta la categoría de análisis y los siguientes niveles, se convierten en ejemplos de dichas categorías.

- Los recuadros acompañados de una palabra en mayúscula AFIRMA, corresponden a una forma narrativa que sustenta la categoría de análisis.

- Las flechas significan: esta categoría se ejemplifica, se apoya, se sustenta en.

- El siguiente nivel corresponde a porciones de discurso en donde se sustenta el uso de estas formas 
narrativas ${ }^{3}$ : Aparece la expresión entre comillas, el nombre del periódico y el título del artículo.

Algunos gráficos visualizan el icono de un texto, acompañado de una mano, denominado: Memo, que en el análisis corresponde a un aspecto teórico a sustentar o polemizar con respecto a la categoría analizada y a las porciones de discurso que lo ilustran.
El propósito de involucrar las redes semánticas-networks en este reporte de investigación es poder visualizar y relacionar los diversos elementos de análisis que permiten argumentar las tendencias de periodismo narradas en las muestras periodísticas seleccionadas. Además, permiten sustentar -a través del cotejo con las apreciaciones de los grupos focales de emisores y lectores- las inferencias a las que llega la investigación.

Para la actual investigación, todas las porciones de discurso corresponden a los textos de los artículos analizados. No se alcanzaron a relacionar en dichos gráficos categorías con fotografías de los artículos.

$4 \quad$ Los gráficos enumerados son las respectivas Redes Semánticas, "Networks", que desde el software categorizaron de manera analítica y progresiva los instigadores. 
GRÁFICO 14. CATEGORÍA FUENTES CIUDADANÍA DEL COMÚN, FC (AFIRMA, DICE, COMENTA...)
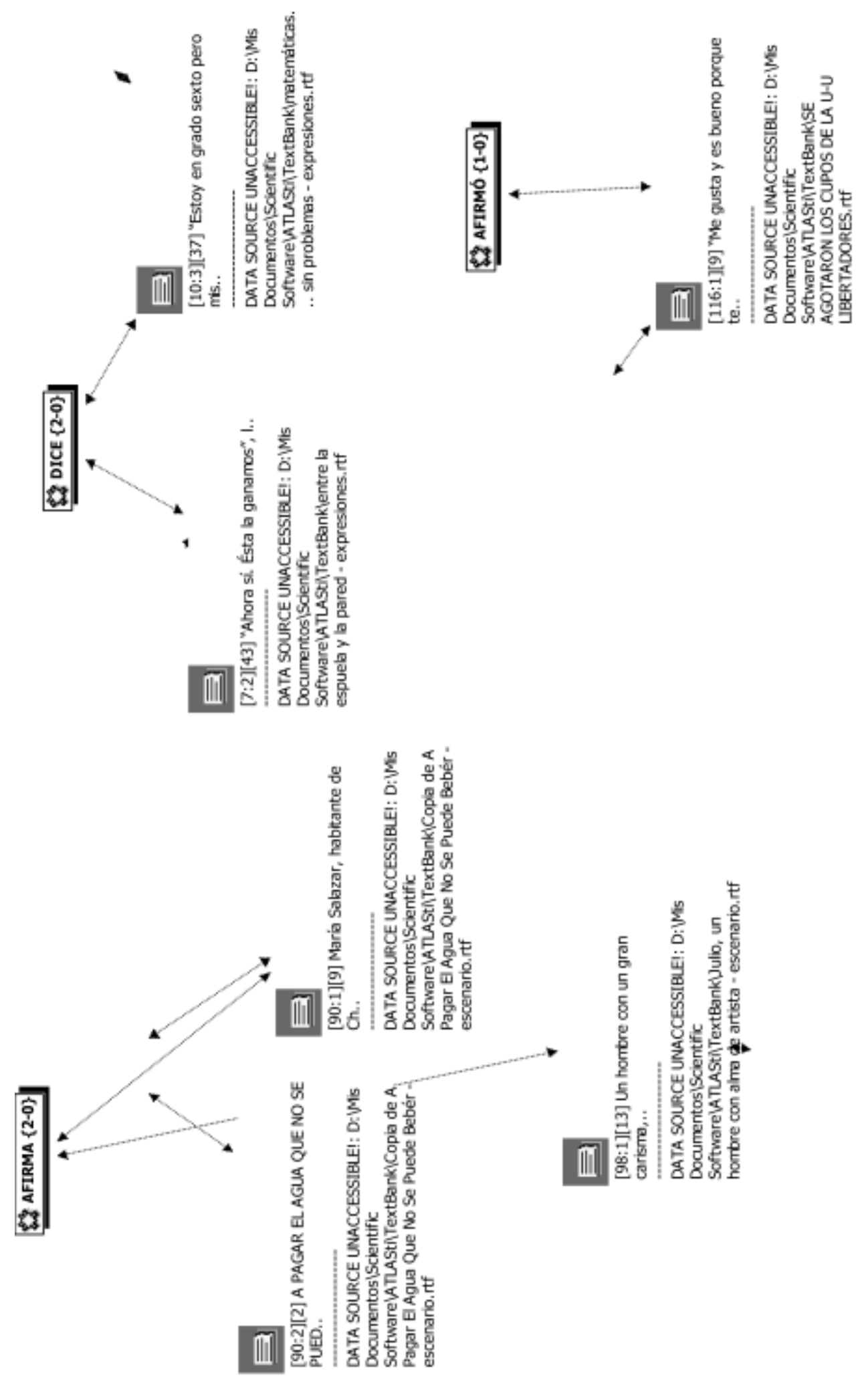

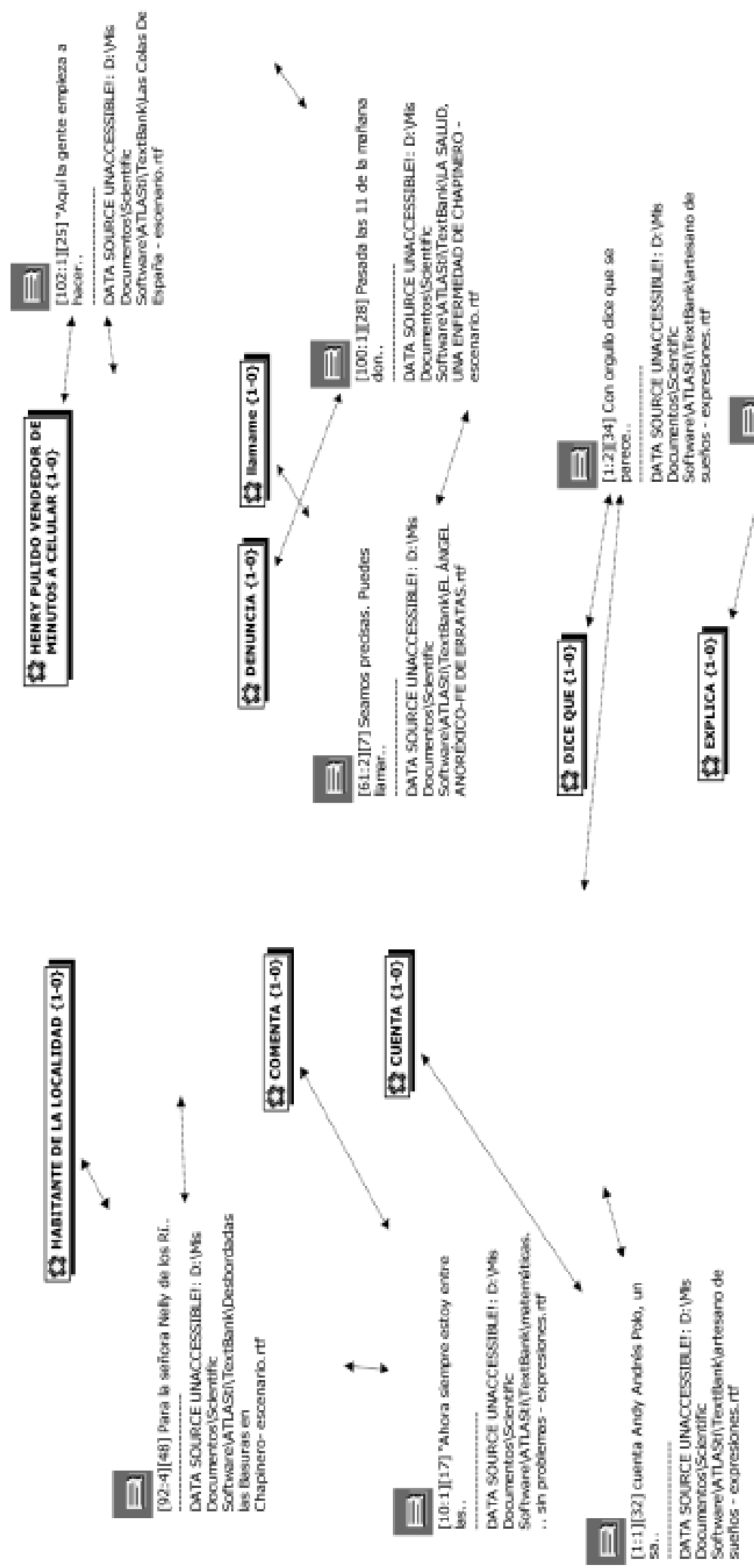
GRÁFICO 2. CATEGORÍA FUENTES AUTORIDADES LOCALES, FAL, AUTORIDADES NACIONALES, FAN, EXPERTOS, FE

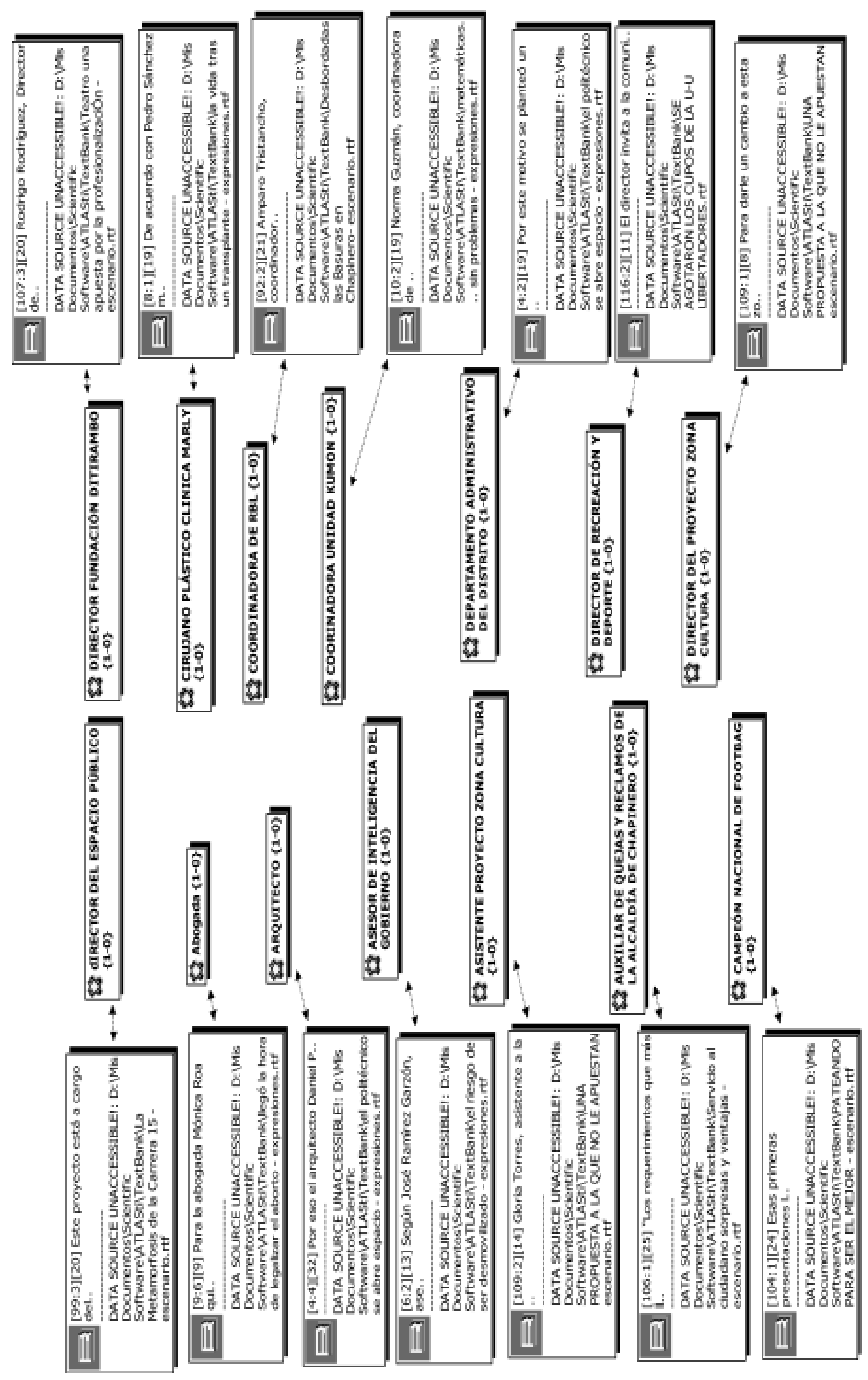



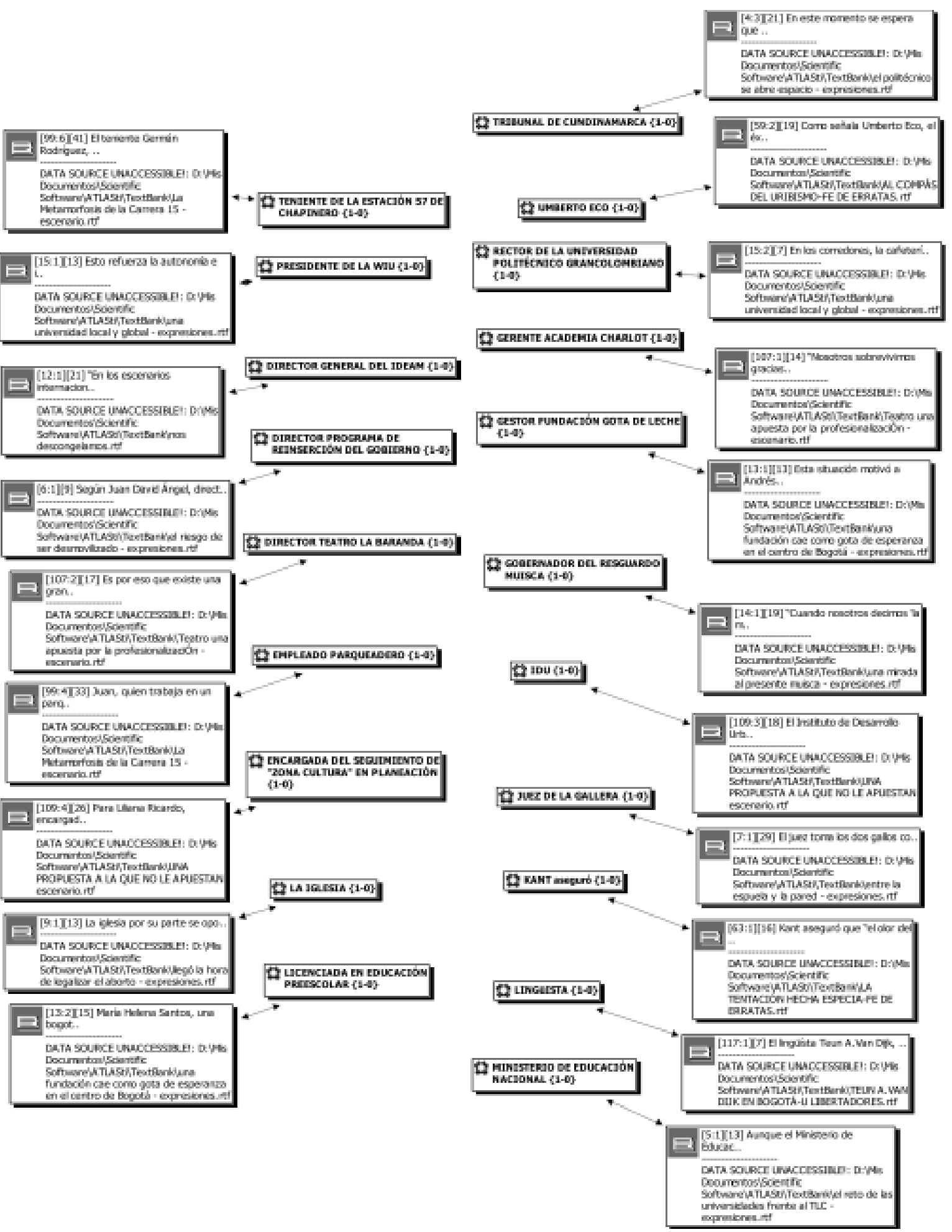
En el Gráfico 1, Fuentes ciudadanía del común, FC, se aprecia que se abren espacios con prelación para dichas voces en las narrativas de los periódicos Expresiones y Escenario, datos que constatan a la vez un segundo elemento de análisis (Temas de interés para la localidad) en la apreciación que brindan los lectores en la encuesta realizada durante la investigación (consúltese Datos de encuesta, en: Chisica Fanny et all, Universidad Santo Tomás, 2006):

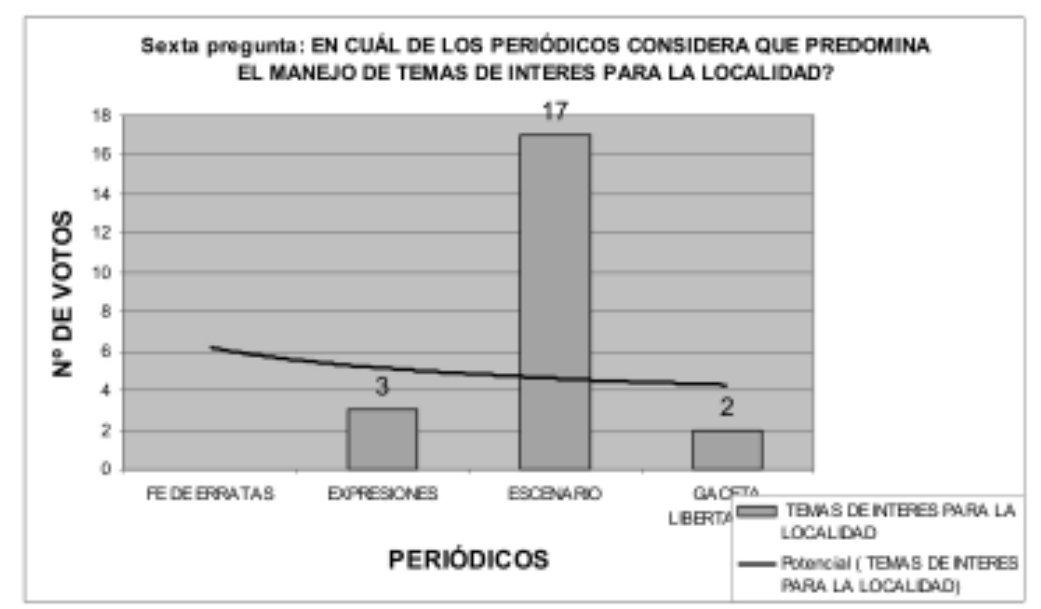

Del Gráfico 2, Fuentes Autoridades locales/nacionales/expertos, se puede inferir que también se brinda la perspectiva con bastante insistencia en la Fuente estructuralmente organizada, como lo diría la investigadora colombiana Ana María Miralles. Es decir, aunque el periodismo universitario intenta que la voz del ciudadano desprevenido pero inquieto y crítico a la vez sea un actor social de este ejercicio periodístico, tiene aún tímida participación en la mesa periodística, de tal manera que resulte sustancial para el sector.

Esta tendencia de participación y lectura que se construye entre las voces del ciudadano del común y aquellas voces denominadas "legítimas" sugieren, a la vez, la percepción de lo que considera este periodismo universitario local como prioritario a narrarse en los cuadernillos de sus ejemplares. Por demás, a la esfera de sus audiencias, si bien es cierto que el periodismo debiera pensarse desde la visibilidad del lector -no ideal, sino diacrónico-, le resulta sustancial temáticas que desde el abordaje de las fuentes evidencien las necesidades del target group lector en cuestión, tal y como se sustenta en la siguiente tabla de datos:

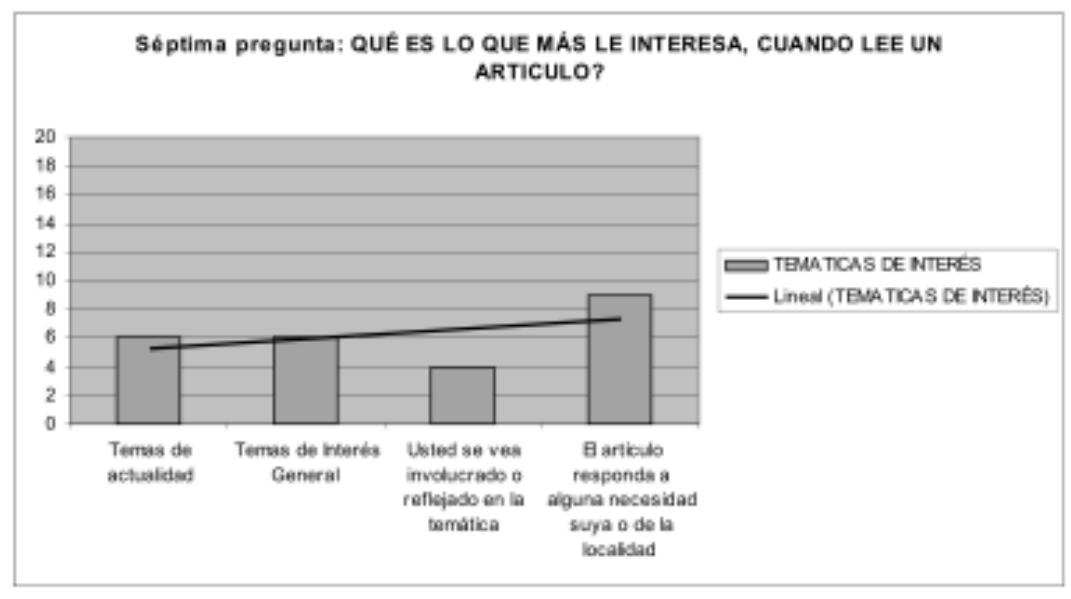


Estas inferencias acompañan una segunda categoría de análisis: Tendencia de titulares, entendiendo que el enunciado titular sintetiza, en el mejor sentido, el contenido de los artículos. Se debe aclarar que dicha categorización es la resultante del proceso de lectura de cada artículo. Se evidenció el comportamiento de realidades del sector que narran ya sea un suceso problema o un suceso solución ante determinado evento que percibe la ciudadanía. Para apreciar en detalle esta relación, se ilustra en los gráficos 3 y 4 la tendencia del Titular problema y Titular solución en el periódico Expresiones (consúltese Datos gráficos titulares, en: Chisica Fanny et all, Universidad Santo Tomás, 2006).

En el consolidado de todos los gráficos se evidencia la preocupación por realidades que inquietan, afectan y/o vivencian -en algunos casos- los miembros de la comunidad universitaria, quienes antes de asumir el rol de comunidad académica son ante todo ciudadanos que empiezan a leer una porción de ciudad, desde la localidad en la que se circunscribe la academia.

El espectro temático sugerido en los titulares abarca situaciones tales como la anorexia, el desplazamiento, el consumo de..., la academia y la economía, la legalización de..., lo científico, la salud mental, el funcionamiento ilegal de..., el talento, los actores del sector, el pasatiempo; todos narrados entre la tímida voz del ciudadano del común y la notoria participación de la voz legítima. No obstante, se debe advertir la naciente apertura por narrativas que rompen con la estilística con- vencional y dan paso a formas argumentativas como la historia de vida, estilística que se insinúa en el periódico Escenario.

Sin dejar de lado el reconocimiento de los lineamientos por una u otra praxis periodística, la actual investigación es una exhortación a la superación de una sociedad monofuentista que en el basto mundo de lecturas miopes de ciudad, de país, de región y, porqué no decirlo, de localidad, dejan en los no lugares de la ausencia la incertidumbre por reconocer si la academia está leyendo los espacios vitales de la ciudad. Es posible que la investigación sugiera algunos de los aspectos que expertos en el periodismo público del país ya han mencionado: ¿desde qué perspectivas de la sociedad el periodismo universitario narra y participa?, ¿cuál es el papel dialógico de este periodismo universitario: la academia por la academia?, ¿la ciudad se debe acercar a la academia o la academia debe adentrarse en la ciudad?

Resulta de vital importancia acercarnos con lupa crítica al tipo de periodismo al que le apuesta la academia, toda vez que es en la academia donde se sugieren los lineamientos de un trabajo de pluma que debiera permear desde y para la ciudad, desde y para sus gentes como actores sociales, autocríticos de su entorno, abiertos al disenso, a los contra públicos y al pluralismo de opinión ${ }^{5}$, por lo tanto, el siguiente gráfico, evidencia unas tendencias de comportamiento de las categorías de fuentes, por ende de voces, que narran y predominan en las muestras periodísticas analizadas (ver Gráfico 6).

Aspectos sugeridos en la revisión que hace la investigadora colombiana Ana María Miralles, en su conferencia "Comunicación y conflicto, hacia la necesidad de politizar los antagonismos", en: Congreso Internacional La comunicación, eje transformador de los conflictos hacia la convivencia pacífica, Bogotá, Universidad Santo Tomás, 6/05/06 (Memorias en proceso). 
GRÁFICO 3. CATEGORÍA TENDENCIA TITULAR PROBLEMA EN EL·PERIÓDICO EXPRESIONES

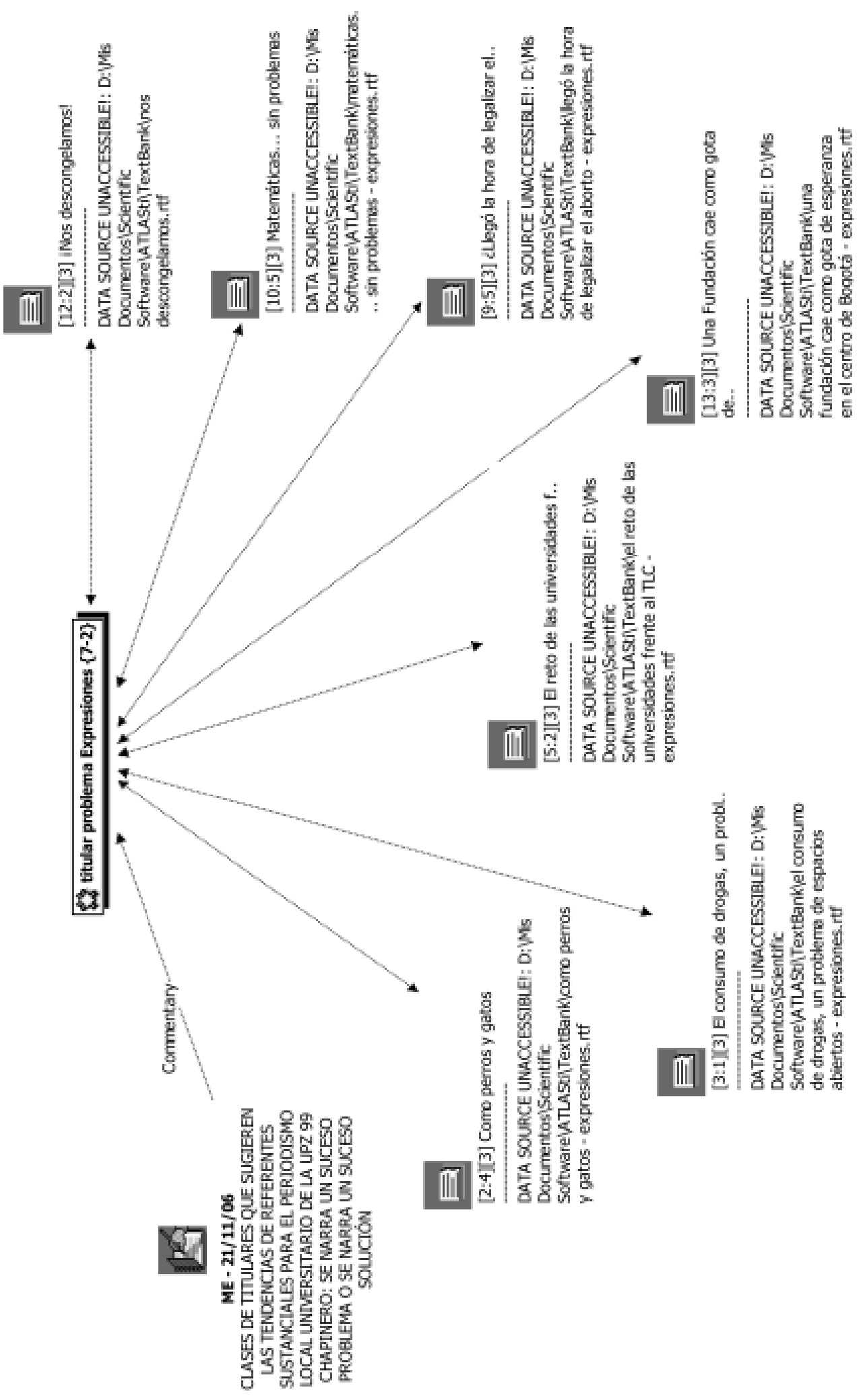


GRÁFICO 4. CATEGORÍA TENDENCIA TITULAR SOLUCIÓN EN EL PERIÓDICO EXPRESIONES

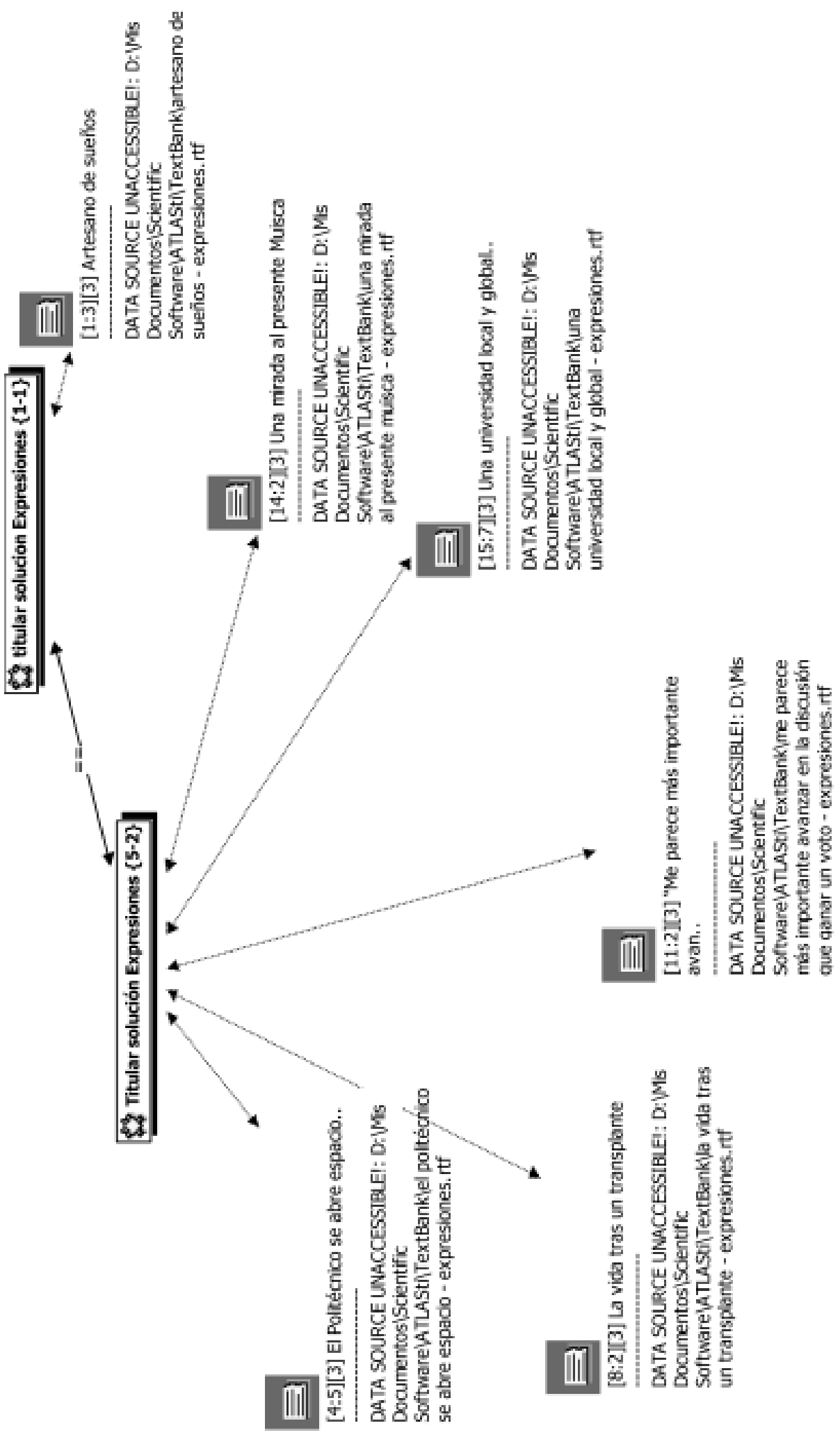


GRAFICO 5. CATEGORÍA TENDENCIA DE ENUNCIADOS TITULARES EN EL PERIODISMO LOCAL UNIVERSITARIO

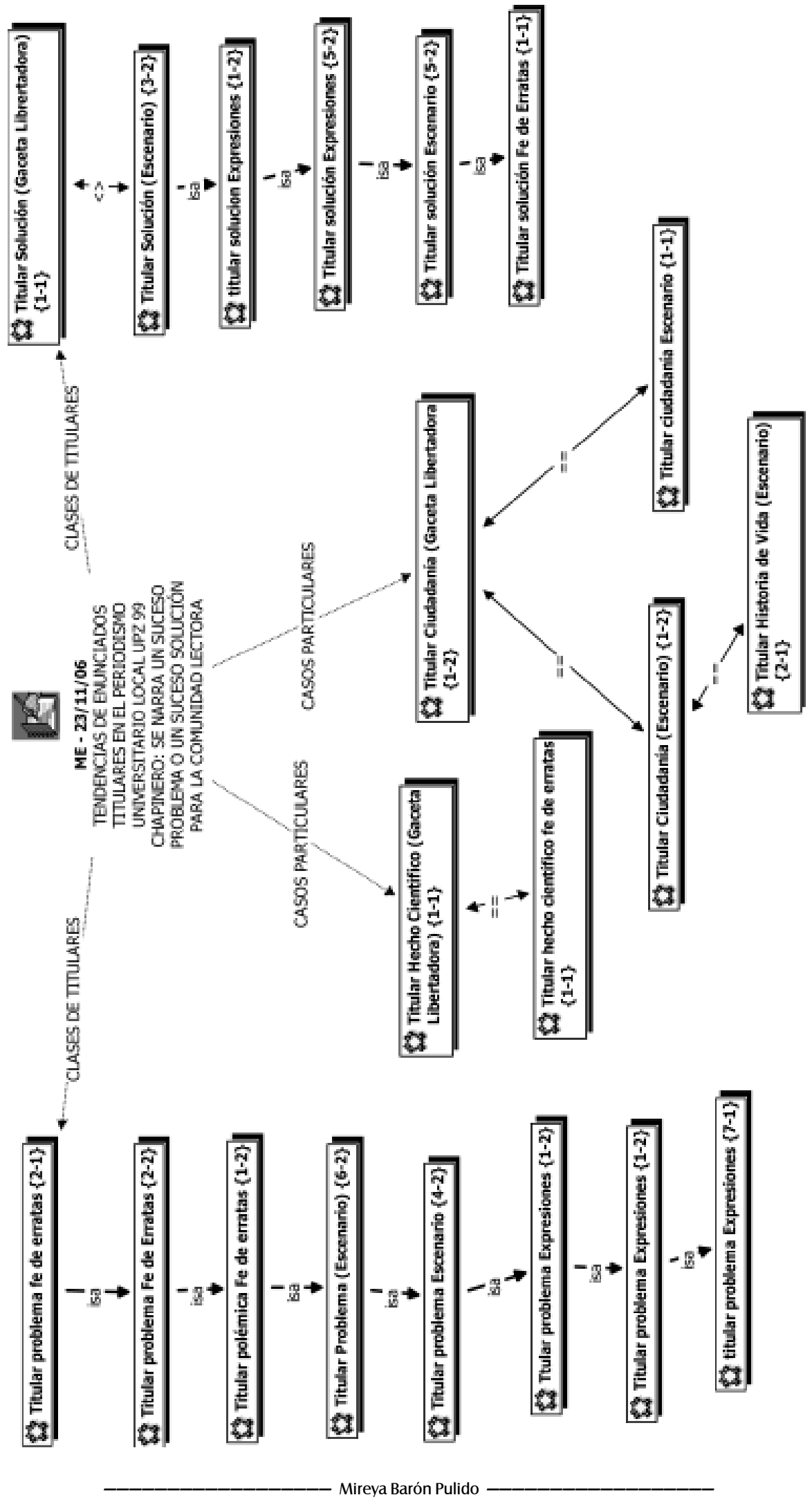


GRÁFICO 6. ¿PERIODISMO PÚBLICO?

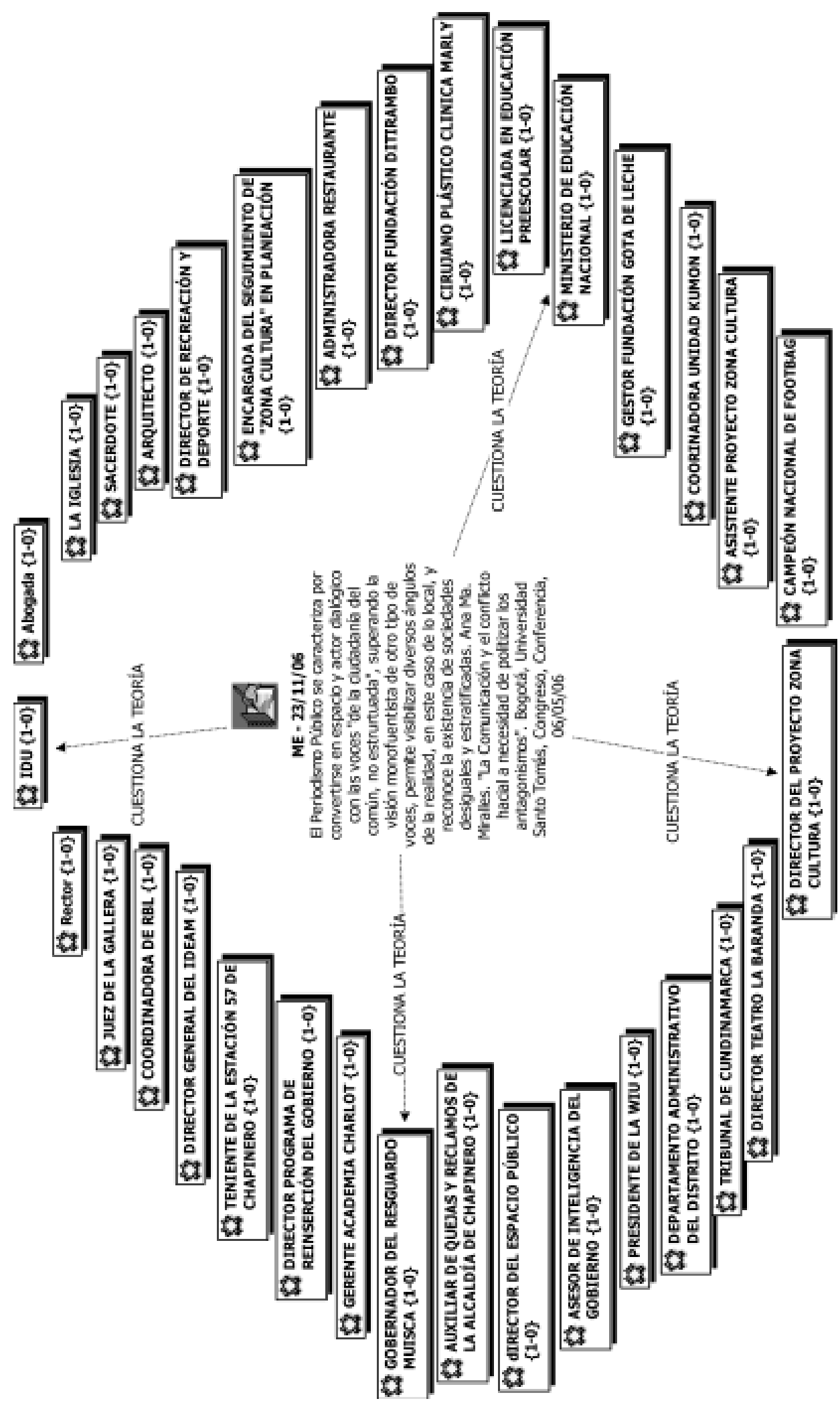


Junto a estas argumentaciones, la investigación logra compilar algunas de las categorías ya mencionadas, teniendo en cuenta las apreciaciones dadas desde la esfera de los emisores, la cual complementa aspectos que caracterizan cada ejercicio periodístico (consúltese Transcripciones sesión grupo focal emisores, en: Chisica Fanny et all, Universidad Santo Tomás, 2006); y los datos que arrojó la encuesta aplicada a la esfera de las audiencias:

\begin{tabular}{|c|c|}
\hline PERIÓDICO ${ }^{6}$ & $\begin{array}{l}\text { APRECIACIONES } \\
\text { GRUPO FOCAL EMISORES }\end{array}$ \\
\hline $\begin{array}{l}\text { GACETA LIBERTADORA } \\
\text { (Segunda Edición) }\end{array}$ & $\begin{array}{l}\text { Fuentes: prelación a fuentes desde la academia. } \\
\text { Temáticas: interés de la comunidad (académica Los Libertadores). } \\
\text { Lo local: la Universidad los Libertadores, temas institucionales. } \\
\text { Tendencias: lo institucional evidenciando las competencias académicas de } \\
\text { los estudiantes. } \\
\text { Escritores: estudiantes de IX-X semestre. }\end{array}$ \\
\hline $\begin{array}{l}\text { FE DE ERRATAS } \\
\text { (Cuarta edición) }\end{array}$ & $\begin{array}{l}\text { Fuentes: prelación a las fuentes de expertos (FE), fuentes primarias. } \\
\text { Temáticas: interés de la comunidad (estudiantil javeriana), desde el } \\
\text { nombre del periódico "tener conciencia del error": cultura-sociedad y } \\
\text { política; temas que afectan al país. } \\
\text { Lo local: la Javeriana. } \\
\text { Tendencias: periodismo local desde las experiencias y cuestionamientos } \\
\text { del estudiante javeriano(a), desde el joven. } \\
\text { Escritores: estudiantes de IV semestre. }\end{array}$ \\
\hline $\begin{array}{l}\text { EXPRESIONES } \\
\text { (Cuarta edición) }\end{array}$ & $\begin{array}{l}\text { Fuentes: prelación a las fuentes primarias. El tema orienta la selección de } \\
\text { fuentes y uso de fuentes de la ciudadanía del común. } \\
\text { Temáticas: cultura-social del país. A la vez problemáticas que atañen a la } \\
\text { localidad. } \\
\text { Lo local: contextos que vive la comunidad (estudiantil Politécnico). } \\
\text { Tendencias: lo social, desarrollo universitario en la zona. } \\
\text { Escritores: estudiantes de III semestre. }\end{array}$ \\
\hline $\begin{array}{l}\text { ESCENARIO } \\
\text { (Novena Edición) }\end{array}$ & $\begin{array}{l}\text { Fuentes: prelación a las fuentes de la ciudadanía del común. } \\
\text { Temáticas: visibilizan problemáticas de la localidad, historias de vida. } \\
\text { Actores: problemáticas de los ciudadanos. } \\
\text { Lo local: contexto. } \\
\text { Tendencias: búsqueda de un periodismo público, periódico de contexto. } \\
\text { Escritores: estudiantes de VII-VIII semestre. }\end{array}$ \\
\hline
\end{tabular}

Los periódicos están organizados de menor a mayor número de ediciones. Se debe aclarar que, desafortunadamente, el Periódico Gaceta Libertadora ya no se edita. 
PREGUNTA DE LA ENCUESTA
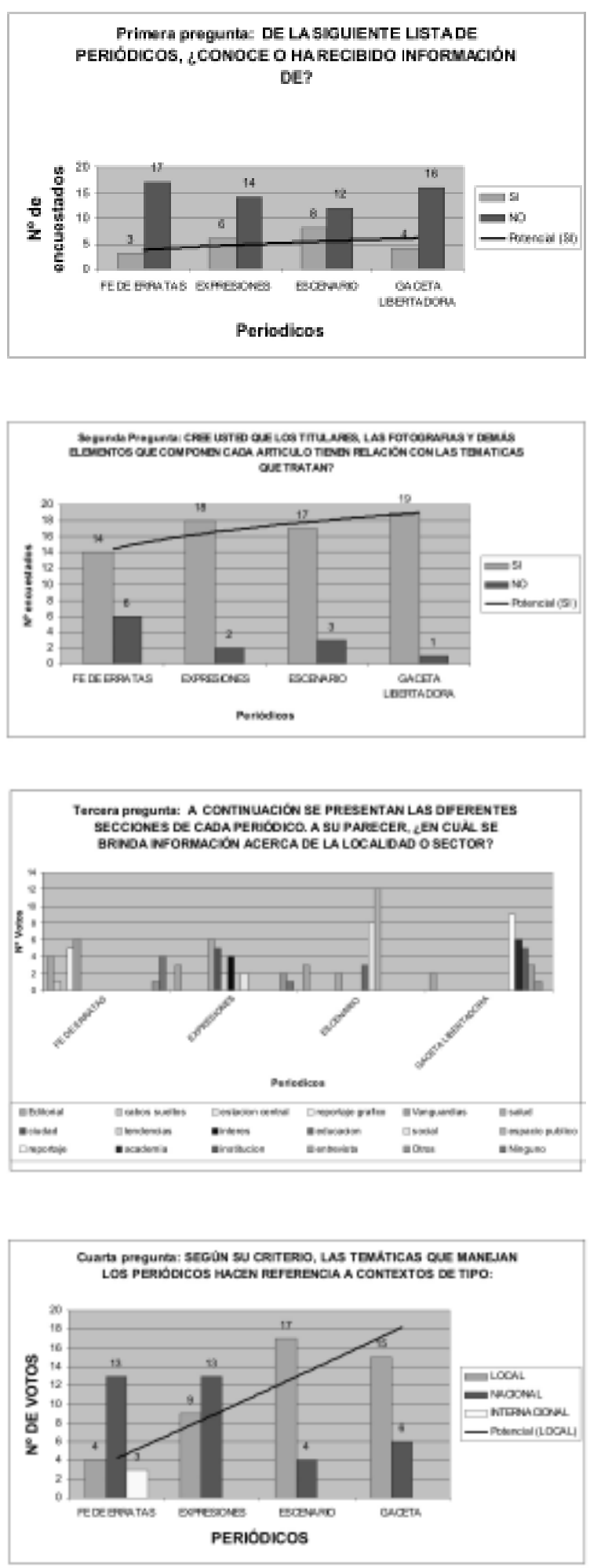

\section{GRUPO FOCAL: AUDIENCIAS ANÁLISIS}

La población lectora reconoce haber tenido conocimiento del periódico Escenario, y le sigue en su orden el periódico Expresiones. Advierten, a la vez, no tener la misma familiaridad con el periódico Fe de Erratas. Este ítem le sugiere a la academia revisar:

La ciudadanía de la localidad es también una población lectora de los medios elaborados desde la academia

La relación entre los enunciados de los titulares y los iconos que le acompañan sugiere alta relación de contenido entre estos elementos discursivos. Destacan el comportamiento de los periódicos Expresiones y Gaceta Libertadora.

En el orden de la gráfica, de izquierda a derecha: para el caso de Fe de Erratas, destacan la sección Vanguardias y Reporte gráfico; aunque es mínima la prelación a este tipo de temáticas. Para el caso de Expresiones, las secciones Salud y Ciudad abordan ejes de la localidad. Para el caso de Escenario, las secciones Espacio público y Social cubren temáticas del sector. Para el caso de Gaceta Libertadora la sección Reportaje destaca temáticas para el sector, aunque resulta relevante la sección Academia, constatándose la apreciación de sus emisores, quienes destacaron que el periódico es un ejercicio institucional.

De los 4 periódicos analizados, los encuestados destacan que Fe de Erratas es el único impreso que dedica atención a temáticas de orden internacional, y sobresale el cubrimiento a sucesos de contexto nacional. Caracterizan el periódico Escenario en el cubrimiento de temáticas de contexto local. 
PREGUNTA DE LA ENCUESTA
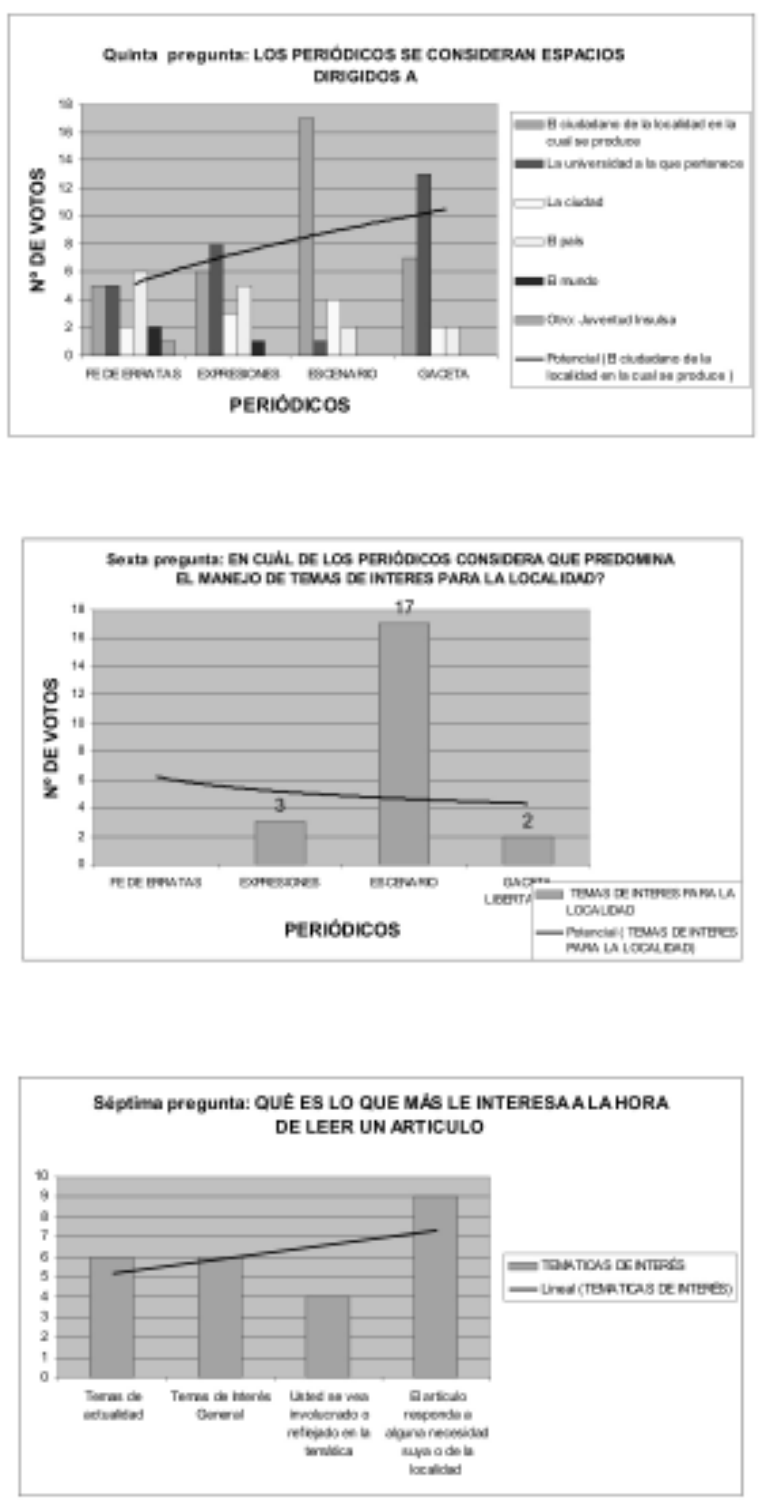

\section{GRUPO FOCAL: AUDIENCIAS ANÁLISIS}

Para los 4 Periódicos se mantiene una oscilación notoria entre dos aspectos que constatan los encuestados: espacios dirigidos al ciudadano de la localidad y espacios dirigidos a la universidad a la que pertenecen. Para Fe de Erratas, aunque es mínimo el tratamiento a estos dos aspectos, resulta equitativo al interior del periódico. Para Expresiones y Gaceta, la relevancia corresponde a la universidad a la que pertenecen, mientras que para Escenario es notoria la prelación de espacios dirigidos al ciudadano de la localidad, pasando a un segundo plano los de la universidad a la que pertenece.

La tendencia de respuesta a esta pregunta es coherente con la tendencia de respuesta a la quinta pregunta: Fe de Erratas no evidencia temas de interés para la localidad, sugiriéndose una vez más que Escenario tiene como prelación abordar temáticas de interés para la localidad.

Los encuestados responden como prioridad en este tipo de ejercicio periodístico que los artículos respondan a las necesidades del lector y/o de la localidad. Esta pregunta alimenta una inferencia de la investigación: Ios periódicos elaborados desde las facultades de comunicación debieran hacer lectura de ciudad, del entorno, más aún, de las localidades, que tienen necesidades que suelen no ser escuchadas ni dialogadas con relevancia por parte de la prensa nacional: se nos invita a ingresar en la consolidación de agendas ciudadanas. 
Teniendo en cuenta las percepciones de los emisores $y$ de los lectores, y las categorías visualizadas en el AC, existe una preocupación por acercarse a narrativas del día a día que, aunque se narran desde las clásicas fuentes legítimas y de autoridad de la sociedad, empiezan a evidenciar el uso de voces de la población ciudadana del entorno, dando cabida al uso de formas discursivas como historias de vida.

Un periodismo que se convierta en observador participante de sus entornos y contextos inmediatos es un periodismo que evidencia las necesidades de su ciudadanía y que por ende plasma una lectura de país, es un periodismo de contexto. El propiciar agendas ciudadanas, no desde las instituciones sino desde la ciudadanía del común, permitirá consolidar planes de acción específicos y mancomunados que favorezcan la calidad de vida en las localidades de una ciudad.

Más que un periodismo público propiciado entre ciudadanía, academia e instituciones de la ciudad, se trata de construir unas formas narrativas que desde "lo local" visualicen no lo "banal" ni la "mera denuncia", con titulares que evocan problemáticas, sino que la sala de redacción urbana emerja desde y para las problemáticas y posibles soluciones del día a día de la ciudadanía del sector, sin olvidar que el mismo comunicador-periodista en formación se convierte en un ciudadano más del sector, con un insumo: el de ser el posibilitador y mediador de estas realidades urbanas y no urbanas.

Los emisores de este ejercicio periodístico deben propiciar unas dinámicas periodísticas que posibiliten la actuación más dialógica desde los sentidos y lenguajes del ciudadano del sector, pensando en la opción de considerar el periodismo como una praxis educativa para la ciudad.

El nivel de impacto que propician los resultados de esta investigación sólo se constatará una vez se socialice este reporte en las universidades que participaron en el proyecto, y en otros espacios de la academia, de las alcaldías, de las JAL (Juntas de Acción Local), de los líderes comunitarios, y de los lectores ciudadanos del sector.

\section{BIBLIOGRAFÍA}

ALCALDÍA DE CHAPINERO, Políticas culturales, Localidad Dos: Chapinero, www.redbogota.com (fecha de consulta: 26/ 01/06).

BARON, Mireya. "Narrãre et Identitas". En: Revista Miradas, Vol. 1, N 1, noviembre de 2005, Bogotá: Universidad Santo Tomás, pp. 41-49.

"Tendencias del periodismo local universitario, una mirada". En: Revista Miradas, Vol. 1, № 3, junio-diciembre de 2006, Bogotá: Universidad Santo Tomás, pp. 283-297.

BONILLA, E. y RODRÍGUEZ, Penélope, Más allá del dilema de los métodos: La investigación en las ciencias sociales. Bogotá: Norma, 1997.

CARVAJAL L., Diógenes, Sistematización y análisis cualitativo con Atlas.ti 5.0, (documento en construcción), Bogotá: Software Shop para América Latina, septiembre de 2006.

COLLE, Raymond, "La visita de Juan Pablo II en diarios de Santiago de Chile". Escuela de Periodismo de la Pontificia Universidad Católica de Chile. En: http:// www.puc.cl/curso_dist/conocer/analcon/index.html (fecha de consulta: 16/02/06).

DAZA H., Gladis. Periodismo y ciudadanía. Bogota: Cedal, Konrad Adenauer, 2000.

HABERMAS, Jürgen. Teoría de la acción comunicativa. 2 vols. Madrid: Taurus, 1998.

KRIPPENDORFF, Klauss. Metodología de análisis de contenido, Comunicación Ediciones. Barcelona: Paidós, 1990.

MIRALLES, Ana María. Periodismo, opinión pública yagenda ciudadana. Bogota: Norma, 2001.

MONZÓN A, Cándido. Opinión pública, comunicación y política. Barcelona: Paidós, 1997. 
ORTEGA, Félix y HUMANES, María Luisa. Algo más que periodismo. Barcelona: Ariel, 2000.

\section{Periódicos universitarios}

Escenario, Facultad de Comunicación Social para la Paz, Universidad Santo Tomás, $N^{\circ} 8$, noviembre de 2005.

Expresiones, Politécnico Grancolombiano, Edición $\mathrm{N}^{\circ} 4$, mayo de 2006.

Fe de Erratas, Facultad de Comunicación y Lenguaje, $N^{\circ}$ 4, mayo/junio de 2006.

Gaceta Libertadora, Fundación Universitaria Los Libertadores, junio de 2005.
TORRICO V., Erick, Abordajes y periodos de la teoría de la comunicación, Bogotá: Norma, 2004.

WIMMER, R., y DOMINICK, Joseph, Introducción a la investigación de medios masivos de comunicación, México: Thomson Learning, 2001.

www.cambiocultural.com.ar (fecha de consulta, junio 25 de 2005). Link: Historia del periodismo público en EE.UU. Link: Investigación de cambio cultural, métodos y técnicas del periodismo público.

www.redbogota.com (fecha de consulta, septiembre 15 de 2005). Link: Secretaría de Gobierno Distrital y Subsecretaría de Asuntos Locales, 2002-2003. Link: Políticas culturales de Chapinero (cartografía). Link: Decreto Ley 1421 de 1993, Acuerdo 13 de 2000, Proyecto Bogotá sin indiferencia. 